\title{
NEW PUBLICATIONS / NOUVELLES PUBLICATIONS
}

Le Centre de recherche en civilisation canadienne-française de l'Université d'Ottawa est heureux d'annoncer la parution de la $3 \mathrm{e}$ édition, entièrement refondue, du Guide des archives conservées au CRCCF, par Danielle Raymond, Lucie Pagé et al., dans la collection «Documents de travail du CRCCF», no 36. Cet instrument de recherche facilite l'accès des usagers à la masse documentaire conservée au Centre, soit 414 fonds et collections totalisant près d'un kilomètre linéaire de documents sur divers supports (documents textuels, photographiques, sonores, vidéo, filmiques, ordinolingues, ainsi que microformes et documents particuliers). Le Guide favorise ainsi la recherche et l'enseignement sur le Canada français, et en particulier sur l'Ontario français. Pour obtenir gratuitement un exemplaire du Guide, veuillez communiquer avec France Beauregard, au CRCCF. Tél.: (613) 564-6847. Téléc.: (613) 564-7174.

The African American Mosaic: A Library of Congress Resource Guide for the Study of Black History and Culture was recently published by the Library of Congress. The volume, which provides an overview of the library's holdings on African American history and culture, includes bibliographies on slavery, discographies of contemporary recordings, descriptions of television documentaries on the Civil Rights era, portrayals of African Americans in popular films, and similar items. For more information, write to the Library of Congress, Public Affairs Office, Washington, DC 20540.

Dictionnaire biographique du Canada, Volume XIII, de 1901 à 1910. Le volume XIII, le premier à aborder le XXe siècle, marque un jalon important dans la publication du DBC. Trois autres volumes doivent couvrir la période comprise entre 1911 et 1940. Rédigées avec beaucoup de rigueur et d'enthousiasme par 438 collaborateurs, les 648 biographies du volume XIII font la chronique de la majeure partie du XIXe siècle; l'ensemble de ces textes brosse le tableau vivant d'une société marquée par une profonde mutation sur les plans culturel et démographique à l'aurore du XXe siècle.

Les grands débats parlementaires, 1792-1992 de Réal Bélanger, Richard Jones et Marc Vallières. À l'aide de multiples sources existantes (journaux d'époque, brochures diverses...), les auteurs ont inventorié et sélectionné 147 grands débats parlementaires et en ont reconstitué les extraits les plus représentatifs qui permettent de mieux comprendre les enjeux des deux derniers siècles de l'histoire du Québec. Pris dans leur ensemble, les 147 grands débats retenus révèlent l'étonnante diversité parlementaire québécoise. Ces débats, présentés par ordre chronologique, sont regroupés selon six thèmes: la Constitution, les institutions parlementaires, l'économie, l'éducation, les questions sociales et la culture, en particulier la langue. Ils témoignent des grandes décisions d'une société qui affectent tout aussi bien son avenir politique que ses grandes orientations sociales, économiques et culturelles.

La cartographie au Québec, 1760-1840 de Claude Boudreau. L'auteur s'est penché sur la production cartographique du territoire québécois entre 1760 et 1840 . Il passe d'abord en revue les méthodes et pratiques de la cartographie de l'époque, puis examine le rôle joué par le Bureau de l'arpenteur général. Il propose ensuite une typologie des cartes d'après leurs fonctions et analyse quelques oeuvres cartographiques d'envergure, dont celles de Murray, de Holland et Collins, de Gale et Duberger, de Vondenvelden et Charland, de Bouchette. À l'aide d'exemples tirés de ces documents, il montre comment l'État ou l'un de ses représentants peut facilement orienter le message cartographique.

Dans Les Wendats. Une civilisation méconnue, Georges E. Sioui effectue un véritable retour aux sources et offre une profonde réflexion sur l'histoire et la nature d'une civilisation du Cercle, la civilisation wendate. L'auteur raconte l'histoire millénaire des Wendats, les ancêtres des Hurons-Wendats, avec la préoccupation qui fut toujours la sienne: retracer l'origine des idées sociales et philosophiques de son peuple et des autres nations amérindiennes. Son objectif est donc celui d'un historien doublé d'un philosophe: montrer ce qu'étaient ce peuple, cette civilisation de façon à mieux connaître et apprécier ce qui en reste aujourd'hui. 